\title{
Correspondence
}

Preliminary efficacy and safety of an oromucosal standardized cannabis extract in

\section{chemotherapy-induced nausea and vomiting}

Marta Duran, ${ }^{1}$ Eulàlia Pérez, ${ }^{1}$ Sergio Abanades, ${ }^{2}$ Xavier Vidal, ${ }^{1}$ Cristina Saura, ${ }^{3}$ Margarita Majem, ${ }^{4}$ Edurne Arriola, ${ }^{5}$ Manel Rabanal, ${ }^{6}$ Antoni Pastor, ${ }^{2}$ Magí Farré, ${ }^{2}$ Neus Rams, ${ }^{6}$ Joan-Ramon Laporte ${ }^{1} \&$ Dolors Capellà ${ }^{1}$

${ }^{1}$ Fundació Institut Català de Farmacologia, Hospital Universitari Vall d'Hebron, Universitat Autònoma de Barcelona, E-08035, ${ }^{2}$ Institut Municipal d'Investigació Mèdica, Hospital del Mar, ${ }^{3}$ Servei d'Oncologia, Hospital Universitari Vall d'Hebron, ${ }^{4}$ Servei d'Oncologia, Hospital de Sant Pau, ${ }^{5}$ Servei d'Oncologia, Hospital del Mar, Cancer Research Program IMIM-Hospital del Mar, Barcelona and ${ }^{6}$ Direcció General de Recursos Sanitaris, Departament de Salut, Generalitat de Catalunya, Barcelona, Spain

\section{WHAT IS ALREADY KNOWN ABOUT}

\section{THIS SUBJECT}

- Orally administered synthetic cannabinoids (nabilone and dronabinol) have been shown to be superior to dopamine receptor antagonists in preventing chemotherapy-induced nausea and vomiting (CINV).

- There is no information on the tolerability of an acute dose titration of a whole-plant

cannabis-based medicine (CBM).

- The efficacy of cannibidiol with

tetrahydrocannabinol added to the current standard therapy in the control of CINV after moderately emetic cancer chemotherapy (MEC) administration has not been established.

\section{WHAT THIS STUDY ADDS}

- This is the first controlled study assessing the tolerability of an acute dose titration of a CBM. - The results suggest that rapid titration of a CBM appeared to be well tolerated by most patients and efficacious in reducing the incidence of delayed CINV.
Dr Marta Duran Delmás, MD, Fundació Institut Català de Farmacologia, Hospital Universitari Vall d'Hebron, Universitat Autònoma de Barcelona, P Vall d'Hebron 129-139, 08035 Barcelona, Spain.

Tel.: + 34934894494

Fax: + 34934894109

E-mail: grupcbm@icf.uab.cat

Keywords

adverse effects, anti-emetic agents, antineoplastic agents, cannabis, clinical trial, nausea, vomiting

Received

25 November 2009

Accepted

25 June 2010

\section{AIMS}

Despite progress in anti-emetic treatment, many patients still suffer from chemotherapy-induced nausea and vomiting (CINV). This is a pilot, randomized, double-blind, placebo-controlled phase II clinical trial designed to evaluate the tolerability, preliminary efficacy, and pharmacokinetics of an acute dose titration of a whole-plant cannabis-based medicine (CBM) containing delta-9-tetrahydrocannabinol and cannabidiol, taken in conjunction with standard therapies in the control of CINV.

\section{METHODS}

Patients suffering from CINV despite prophylaxis with standard anti-emetic treatment were randomized to CBM or placebo, during the $120 \mathrm{~h}$ post-chemotherapy period, added to standard anti-emetic treatment. Tolerability was measured as the number of withdrawals from the study during the titration period because of adverse events (AEs). The endpoint for the preliminary efficacy analysis was the proportion of patients showing complete or partial response.

\section{RESULTS}

Seven patients were randomized to CBM and nine to placebo. Only one patient in the CBM arm was withdrawn due to AEs. A higher proportion of patients in the CBM group experienced a complete response during the overall observation period [ $5 / 7$ (71.4\%) with CMB vs. $2 / 9$ (22.2\%) with placebo, the difference being $49.2 \%(95 \% \mathrm{Cl} 1 \%, 75 \%)]$, due to the delayed period. The incidence of AEs was higher in the CBM group ( $86 \%$ vs. $67 \%$ ). No serious AEs were reported. The mean daily dose was 4.8 sprays in both groups.

\section{CONCLUSION}

Compared with placebo, CBM added to standard antiemetic therapy was well tolerated and provided better protection against delayed CINV. These results should be confirmed in a phase III clinical trial. 


\section{Introduction}

Chemotherapy-induced nausea and vomiting (CINV) remains a significant problem in cancer patients, with nausea being one of the most stressful reported events [1]. Although the use of 5-hydroxytryptamine receptor $\left(5-\mathrm{HT}_{3} \mathrm{R}\right)$ antagonists and neurokinin- $1\left(\mathrm{NK}_{1}\right)$ inhibitors has reduced the rates of acute emesis, their effects on delayed nausea and vomiting, mainly in patients receiving moderately emetogenic cancer chemotherapy (MEC), are not entirely satisfactory $[2,3]$. In fact, an unknown proportion of this group of patients self-medicate with cannabis to treat CINV in our country [4].

In the past decade, cannabinoids (the active components of (annabis sativa) and the endocannabinoid system have come under intense scrutiny following the discovery of $C B 1$ and $C B 2$ receptors and the development of specific cannabinoid receptor agonist and antagonist ligands [5]. It has been suggested that the endocannabinoid system inhibits emesis physiologically, by activating the CB1 and $C B 2$ receptors localized in the dorsal vagal complex of the brainstem where emetic reflexes are integrated [6]. The same activation is produced by the administration of exogenous cannabinoids [7].

A systematic review of 30 clinical trials involving orally administered synthetic cannabinoids (nabilone and dronabinol) showed that they were superior to dopamine receptor antagonists in preventing CINV [8]. Both are approved by the US Food and Drug Administration for use in CINV refractory to conventional anti-emetic therapy, but some authors have questioned the appropriateness of orally administered cannabinoids due to the variability in their gastrointestinal absorption, low bioavailability, long half-lives and the difficulties for an adequate self titration of the dose [9].

Animal studies suggest that the combined administration of different cannabinoids may enhance some of the therapeutic effects of delta-9-tetrahydrocannabinol (THC) [10]. This might explain why some patients preferred marihuana to synthetic cannabinoids in clinical trials [9].

On the basis of these arguments, current clinical research has focused on cannabis extracts of known standardized active ingredients including both THC and cannibidiol (CBD) [11], and on new administration routes (sublingual, transdermal, inhaled, rectal) in order to improve the scarce bioavailability of the oral route [9].

The cannabis-based medicine (CBM) used in our study (Sativex ${ }^{\circledR}$ ) contains a mixture of THC and CBD in a ratio of approximately $1: 1$, together with small amounts of other cannabinoid derivatives, delivered via an oromucosal spray. Following a single buccal administration, maximum plasma concentrations of both CBD and THC typically occur within 2 to $4 \mathrm{~h}$. The resultant concentrations in the blood are lower than those obtained by inhaling the same dose because absorption is slower, redistribution into fatty tissues is rapid and additionally some of the THC under- goes hepatic first pass metabolism to $11-\mathrm{OH}-\mathrm{THC}$. CBM have shown modest positive results in neuropathic pain associated with multiple sclerosis after a slow titration dose period of 10 to 15 days [12-14]. Information regarding a faster titration dose period to reach the maintenance dose within the first $48 \mathrm{~h}$ to treat acute symptoms of CINV is lacking.

This pilot, exploratory randomized, double-blind, parallel and placebo-controlled phase II clinical trial was designed to evaluate the tolerability, preliminary efficacy, and pharmacokinetics of an acute dose titration of CBM added to standard therapy in the control of CINV after MEC administration.

\section{Methods}

\section{Design}

This was a naturalistic i.e. aiming to simulate the real-world setting as much as possible, double-blind, pilot, parallel, placebo-controlled phase II clinical trial. All patients gave their written informed consent to participate in the study in accordance with applicable ethical requirements, including approval by the Ethics Committees of the participating hospitals. The study was sponsored by the local Department of Health, and it was conducted at the Oncology Services of three University hospitals in Barcelona.

\section{Patients}

Patients older than 18 years and with a Karnofsky score $\geq 70$ with CINV lasting more than $24 \mathrm{~h}$ according to the MANE questionnaire [15], despite prophylaxis with standard anti-emetic treatment after the administration of 1-day MEC [carboplatin, cisplatin ( $\leq 50 \mathrm{mg} \mathrm{m}^{-2}$ ), cyclophosphamide ( $\left.\leq 1500 \mathrm{mg} \mathrm{m}^{-2}\right)$, doxorubicin $\left(\geq 60 \mathrm{mg} \mathrm{m}^{-2}\right)$, idarubicin, ifosfamide, irinotecan, mitoxantrone $\left(\leq 15 \mathrm{mg} \mathrm{m}^{-2}\right)$ or epirubicin $\left(\leq 90 \mathrm{mg} \mathrm{m}^{-2}\right)$ ] were enrolled during the following chemotherapy cycle.

Standard anti-emetic treatment included corticosteroids as well as $5-\mathrm{HT}_{3} \mathrm{R}$ antagonists or metoclopramide. The study drug was added to the standard treatment during the study cycle. All the patients had histologically confirmed solid tumours. The primary exclusion criteria included the following: current use of illicit drugs, THC or alcohol abuse confirmed by the Insta-Check rapid urine screen, abnormal laboratory values (including WBC $<3000 \mathrm{~mm}^{3}$, platelet count $<100000 / \mathrm{mm}^{3}$, AST $>2.5 \times$ upper limit of normal (ULN), ALT $>2.5 \times$ ULN or creatinine $>1.5 \mathrm{mg} \mathrm{dl}^{-1}$ ), multiple-day chemotherapy in a single cycle, radiation therapy on the abdomen or pelvis within 1 week before or during the study, or cannabinoid (cannabis, Marino ${ }^{\circledR}$ or Nabilone ${ }^{\circledR}$ ) use within 30 days prior to enrolment. Patients were not eligible if they had a history of major psychiatric disorder, severe cardiovascular disease, seizures, were pregnant or lactating, or had suspected 
hypersensitivity to cannabinoids. Patients were advised not to drive during the study.

\section{Procedures}

Patients who met the inclusion criteria were randomly assigned to CBM or placebo. Randomization was stratified by sex and hospital. Treatment allocation was made using randomized permuted blocks of four (two active drug, two placebo), with treatments sequentially assigned to either a CBM containing THC and CBD, administered as an oromucosal spray, or placebo. Each spray push delivered $2.7 \mathrm{mg}$ of THC and $2.5 \mathrm{mg}$ of CBD or placebo. Placebo was designed to match the appearance, smell and taste of the active formulation, but contained no active components.

On the first day of treatment at the hospital outpatient day clinic, up to three sprays were delivered in a $2 \mathrm{~h}$ period following the administration of the corresponding chemotherapy cycle (day 0). If no signs of intoxication were observed after the first dose (time 0 ), a second and a third spray were administered after 30 (time 1) and $120 \mathrm{~min}$ (time 2), respectively. If two consecutive doses were omitted because of adverse events (AEs), the patient was withdrawn from the study. No specific target dose was set and patients were advised to increase home-dose titration until day 4 inhaling up to $\leq 8$ sprays within any $4 \mathrm{~h}$ period every $24 \mathrm{~h}$.

Five blood samples were collected from each patient in heparinized tubes, centrifuged, and the plasma was stored at $-20^{\circ} \mathrm{C}$ until analysis. Three samples were collected at time 0 (basal), 60 and 240 min on day 0 . On day 1, a nurse collected one pre-dose sample at $08.00 \mathrm{~h}$ (basal) and one sample after $60 \mathrm{~min}$ from the patients' home. Samples were obtained after verifying that patients were not consuming cannabis preparations (on day 0 at pre-dose) and for the pharmacokinetic analysis of CBM active principles.

\section{Assessments}

A patient diary was completed during the study to collect the number of vomits and the severity of nausea measured by VAS before the administration of each dose of the study drug during the $120 \mathrm{~h}$ period (days 0 to 4) post chemotherapy. To check for compliance and safety, daily telephone interviews were also conducted. AEs were recorded through the patients' diary and daily telephone interviews, by means of a structured questionnaire.

The MANE questionnaire was used to assess the frequency and duration of nausea and vomiting at basal and final visits. The Functional Living Index-Emesis (FLIE) [16] was used to assess quality of life at basal and final visit. Detailed information about chemotherapeutic agents and anti-emetics were collected from medical records at the basal and final visits.

\section{Analysis of cannabinoids}

Plasma concentrations of THC, CBD and the two metabolites of THC (11-OH-THC and THC-COOH) were measured using a modified previously described method known as the trimethylsilyl derivatives by GC/MS [17]. The lower limit of sensitivity for all compounds was $0.5 \mathrm{ng} \mathrm{ml}^{-1}$.

\section{End points}

Tolerability was measured as the number of patients who withdrew from the study during the titration period because of AEs.

The end point for the preliminary efficacy analysis was the proportion of patients showing complete or partial response. Complete response was defined as no vomiting and a mean nausea VAS score of $\leq 10 \mathrm{~mm}$ and partial response was defined as vomiting on average one to four times daily and a mean nausea VAS score of $\leq 25 \mathrm{~mm}$ during the overall observation period $(0-120 \mathrm{~h}$ post chemotherapy). Secondary end points included the absence of emesis, no significant nausea (VAS score $<25 \mathrm{~mm}$ ), the proportion of patients with reduced frequency, duration and severity of CINV, the impact of CINV on daily life and the percentage of patients and doctors satisfied with the treatment. The proportion of patients with any AEs was estimated.

\section{Statistical analysis and sample size calculation} Analysis was based on the intention-to-treat (ITT) population, including all patients randomized to active treatment or placebo who took at least one dose and had at least one post treatment assessment. The response criteria were applied to the overall observation period $(0-120 \mathrm{~h})$ and also to the acute $(0-24 \mathrm{~h})$ and delayed phase periods (24$120 \mathrm{~h}$ ), although analysis was not planned for acute phase nausea. Treatment comparisons were based on the differences between proportions [18] for categorical variables, and on non-parametric tests for continuous variables. The sex and study site were the prespecified baseline stratification factors. Because it was an exploratory study, no calculation of sample size was made. However, the study was scheduled to enrol 60 patients (30 in each treatment group). Standard programmes were used for data analysis (Confidence Interval Analysis 2.1.2, 2004; SPSS 12.0, 2004. Chicago: SPSS Inc.).

\section{Results}

\section{Study population}

Between January 2006 and December 2007, 50 patients were screened, of whom 16 were randomized (seven to the CBM group and nine to the placebo group) and included in the ITT analyses (Figure 1). All the patients completed the study. One patient in the CBM group discontinued treatment after three sprays at the hospital because of anxiety, somnolence, visual hallucinations, and confusion, all of which disappeared within $3 \mathrm{~h}$.

The baseline patient epidemiological characteristics, including known risk factors for CINV (being female, 


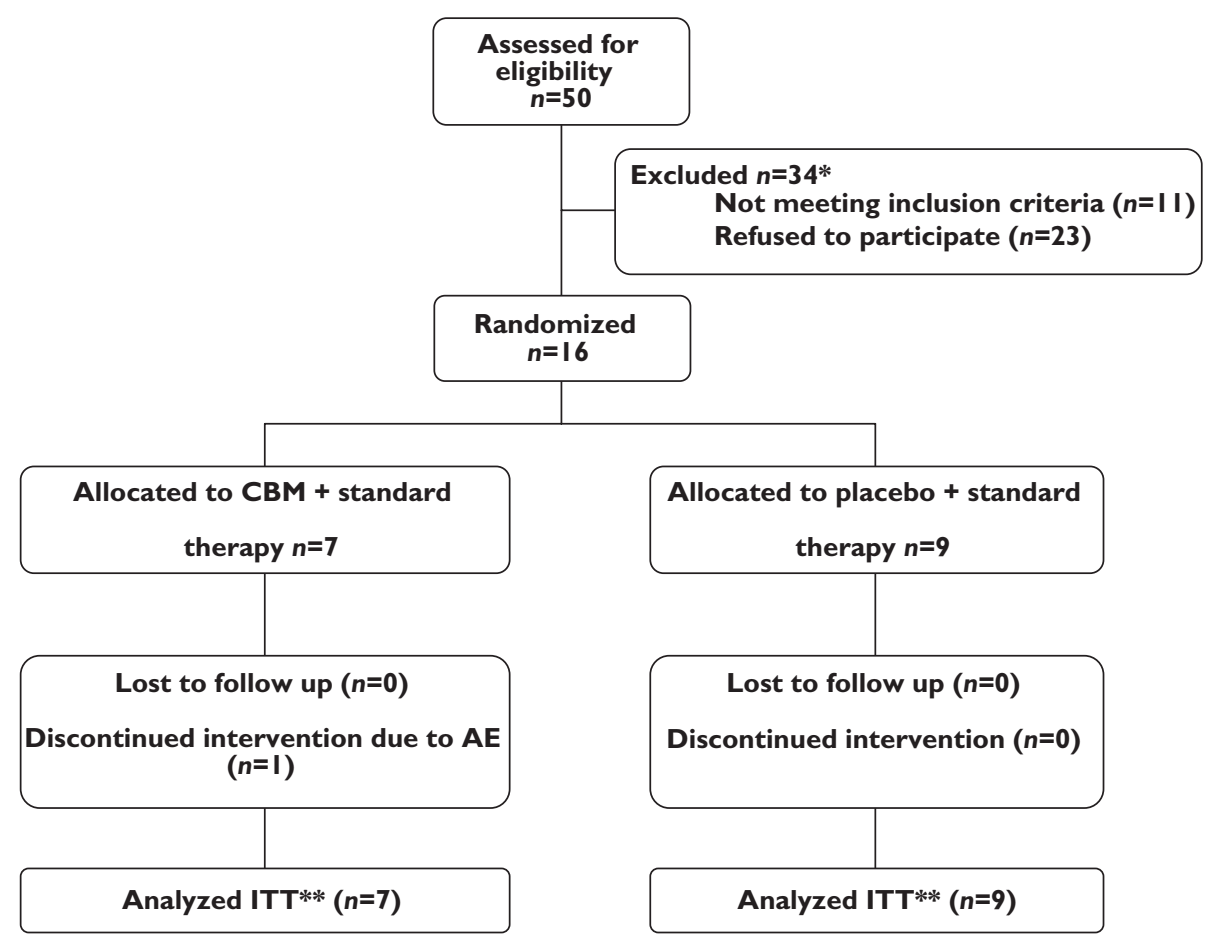

\section{Figure 1}

Study flow chart. *Excluded: 11 patients had an exclusion criteria (participation in other clinical trials, 5 ; use of cannabinoids during the previous 30 days, 1 ; illicit drug use during the previous 30 days, 1; psychiatric disease, 1; end of chemotherapy 1; did not understood the language, 2); 23 patients declined to participate because the study drug was only administered in one cycle. ${ }^{* *}$ ITT: intention-to -treat

history of alcohol use or motion sickness) were similar in each of the treatment groups (Table 1). Only two patients, one in each treatment group, had previously been exposed to cannabis. Almost all the patients in the placebo group had breast cancer. The primary cancer diagnosis in the CBM group was more variable and a higher percentage of patients had metastases. Concomitant anti-emetic for the prevention of acute CINV in the study cycle and the number of previous chemotherapy cycles were similar in both groups. All the patients received concomitant anti-emetic treatment for acute CINV, the most frequent being the association of a corticosteroid and a $5-\mathrm{HT}_{3} \mathrm{R}$ antagonist (ondansetron, granisetron or tropisetron) (Table 2). Almost half the patients in both treatment groups did not receive any prophylaxis for delayed CINV during the study cycle (Tables 1 and 2). Maintenance of the corticosteroid in addition to a $5-\mathrm{HT}_{3} \mathrm{R}$ antagonist (ondansetron and tropisetron) during days 1 to 4 after chemotherapy was the most common antiemetic regimen in both groups (Table 2). The baseline differences in the severity of CINV and basal quality of life were not clinically relevant.

\section{Dosing}

The mean number of daily sprays taken during the 4 days after chemotherapy was 4.81 in the CBM group (range 2.7$5.0, \mathrm{SD}=1.01$ ), equivalent to $12.9 \mathrm{mg}$ of $\mathrm{THC}$ and $12 \mathrm{mg}$ of
$\mathrm{CBD}$, and 4.78 in the placebo group (range 2.9-5.0, $\mathrm{SD}=$ 0.79). The median duration of treatment was 3 days in the CBM group (range 1-5) and 4 (range 3-5) in the placebo group.

\section{Tolerability}

Six out of the seven patients in the CBM group and all the patients in the placebo group tolerated dose titration. One female patient in the CBM arm discontinued treatment after three sprays at the hospital because anxiety, somnolence, visual hallucinations, and confusion occurred although all symptoms disappeared within $3 \mathrm{~h}$. Six patients (86\%) in the CBM group and six (67\%) in the placebo group developed at least one $\mathrm{AE}$ (difference $19 \%, 95 \% \mathrm{Cl}-23.7 \%$, $52.4 \%)$. AEs were considered severe in two patients: one patient in the CBM arm described above and one in the placebo group suffered from severe fatigue and mild somnolence and dysgeusia with vomiting. Somnolence, dry mouth and fatigue were the most common AEs in both groups (Table 4). Three patients in the CBM group (41\%) and one in the placebo group experienced dizziness. Neuropsychiatric AEs were more common among patients randomized to CBM. No serious AEs occurred. No significant changes were seen in either group in terms of blood pressure, weight, temperature, haematology or blood chemistry. 


\section{Table 1}

Baseline characteristics

\begin{tabular}{|c|c|c|}
\hline & $\begin{array}{l}\text { CBM group } \\
n=7\end{array}$ & $\begin{array}{l}\text { Placebo group } \\
n=9\end{array}$ \\
\hline Sex, female/male & $7 / 0$ & $8 / 1$ \\
\hline \multicolumn{3}{|l|}{ Age (years) } \\
\hline Median & 50 & 50 \\
\hline Range & $41-70$ & $34-76$ \\
\hline $\begin{array}{l}\text { Alcohol consumption* (units } \\
\text { per week) }\end{array}$ & 4 & 5 \\
\hline $0-1$ & $2+$ & $2 \neq$ \\
\hline $2-10$ & 1 & 2 \\
\hline$>10$ & 1 & 1 \\
\hline Previous cannabis use $\S$ & 1 & 1 \\
\hline History of motion sickness & 1 & 2 \\
\hline \multicolumn{3}{|l|}{ Primary cancer diagnosis } \\
\hline Breast & 4 & 8 \\
\hline Ovary & 2 & 0 \\
\hline Lung & 1 & 1 \\
\hline \multicolumn{3}{|l|}{ Cancer extension } \\
\hline Localized & 4 & 9 \\
\hline Metastasized & 3 & 0 \\
\hline \multicolumn{3}{|l|}{ Previous QT cycles } \\
\hline 1 & 5 & 6 \\
\hline $3-4$ & 2 & 3 \\
\hline \multicolumn{3}{|c|}{$\begin{array}{l}\text { Concomitant antiemetic treatment for delayed nausea and vomiting in } \\
\text { the study cycle (days } 1 \text { to } 4 \text { ) }\end{array}$} \\
\hline None & 3 & 4 \\
\hline $\begin{array}{l}\text { Corticosteroid }+5-\mathrm{HT}_{3} \\
\text { antagonist }\end{array}$ & 3 & 3 \\
\hline $5-\mathrm{HT}_{3}$ antagonist & 1 & 1 \\
\hline Ortopramide & - & 1 \\
\hline \multicolumn{3}{|l|}{ Basal MANE } \\
\hline \multicolumn{3}{|l|}{ Nausea } \\
\hline Severity mean (SD) & $63.6(26.5)^{\star *}$ & $56.22(20.3)^{\star *}$ \\
\hline Duration (h) mean (SD) & $15.0(7.9)$ & $15.3(10.9)$ \\
\hline \multicolumn{3}{|l|}{ Vomiting } \\
\hline Severity mean (SD) & $52.3(32.9)+\dagger$ & $64.3(22.8)+\dagger$ \\
\hline Duration (h) mean (SD) & $11.6(11.0)$ & $11.1(10.0)$ \\
\hline \multicolumn{3}{|l|}{ Basal FLIE } \\
\hline Median (range) & $67.0(18.0-96.0) \neq \neq$ & $54.0(26.0-110.0) \neq \neq$ \\
\hline
\end{tabular}

*Some use. + Use of $<1$ unit per month. $\neq$ Use $\geq 1$ unit per month. §Recreational use. ${ }^{*} P=0.711$. $\dagger+P=0.427 . \quad \neq \neq P=0.916$. MANE, Morrow assessment of nausea and emesis; FLIE, Functional Living Index-Emesis; SD, standard deviation.

Fifty-seven percent (4/7) of the patients in the CBM group and $88 \%(8 / 9)$ in the placebo group were satisfied with their treatment.

\section{Preliminary efficacy}

The proportion of patients showing complete response in the overall period was significantly higher in the CBM group [5/7 (71.4\%) vs. $2 / 9$ (22.2\%), a difference of $49.2 \%$, $95 \% \mathrm{Cl} 1 \%, 75 \%]$, due to the delayed period [5/7 (71.4\%) vs. $2 / 9(22.2 \%)]$, with no differences in the acute period [5/7 (71.4\%) vs. $6 / 9$ (66.7\%), a difference of $4.8 \% 95 \% \mathrm{Cl}-36.7 \%$, 42.1\%]. One patient in the CBM group and five patients in the placebo group had a partial response.

The CBM regimen was also significantly better than placebo in the secondary and exploratory end point of delayed emesis (Table 3 ). The severity and duration of nausea and vomiting seemed better in the CBM regimen, although the differences were not significant. There were no differences in the quality of life measurements in the two groups (no patients in either group scored $>108$ in the FLIE questionnaire),

\section{Pharmacokinetics of CBM active principles}

Plasma concentrations of THC and CBD were, respectively, $5.5 \pm 6.3$ and $4.7 \pm 5.6 \mathrm{ng} \mathrm{ml}^{-1}$ at $240 \mathrm{~min}$ on day 0 . The active metabolite of THC (11-OH-THC) and the inactive metabolite ( $\mathrm{THC}-\mathrm{COOH})$ were also detected $(5.4 \pm 3.9$ and $16 \pm 9.6 \mathrm{ng} \mathrm{ml}^{-1}$, respectively). No active principles or metabolites were detected at pre-dose or after $60 \mathrm{~min}$ on day 0 in patients in either treatment group. On day 1 predose, THC and CBD were detected in two out of the seven patients randomized to the CBM treatment, and $11-\mathrm{OH}-$ THC in five patients. Sixty minutes after CBM administration, plasma THC was detected in two patients and CBD and $11-\mathrm{OH}-\mathrm{THC}$ was found in four patients. THC-COOH was also detected $\left(17.4 \pm 5.5 \mathrm{ng} \mathrm{ml}^{-1}\right)$ at pre-dose on day 1 in all patients who received the CBM treatment (Figure 2).

\section{Discussion}

In this study a short titration dose from an oromucosal spray of CBM (Sativex ${ }^{\circledR}$ ) was well tolerated. Only one patient in the CBM arm was withdrawn due to AEs. Although AEs were more common in the CBM group (86\% vs. $67 \%$ ), they were either mild or moderate. Somnolence was the most frequently reported $A E$ in both study groups. However, it has also been considered as a beneficial effect in this setting [8]. Other neuropsychiatric AEs were more frequently reported among CBM-treated patients, but in general they were either mild or moderate. The median dose was four sprays per day for 4 days after MEC.

Regarding the preliminary efficacy, this study suggests a better effect of CBM in reducing the incidence of delayed CINV in patients receiving MEC. No differences in quality of life measured by the FLIE questionnaire were seen.

We included an AC regimen as MEC because the study was designed before the publication of the 2006 new Guideline for antiemetics in Oncology from the American Society of Clinical Oncology (ASCO) where the recommendation for regimens including AC was the same as for high emetogenic risk regimens with cisplatin.

Previous studies have suggested an anti-emetic efficacy of cannabinoids compared with phenothiazines, ortopramides and placebo in patients treated with MEC regimens [8]. However, when these studies were performed, the current CINV treatment of reference, the $5-\mathrm{HT}_{3} \mathrm{R}$ antagonists, was not available. On the other hand, the results of our study differ from the most recent clinical trial of dronabinol (at a median dose of $20 \mathrm{mg} \mathrm{day}^{-1}$ for 5 days) in the treatment of delayed MEC induced nausea and vomiting in which the combination of dronabinol and 


\section{Table 2}

Drug regimens for the prevention of CINV concomitant to the study cycle

\begin{tabular}{|c|c|c|c|}
\hline $\begin{array}{l}\text { Treatment for the prevention of CINV } \\
\text { Acute (Day 0) }\end{array}$ & Delayed (Day 1 and day 4) & $\mathrm{CBM} n=7$ & Placebo $n=9$ \\
\hline GRA $2 \mathrm{mg}$ (p.o.) + DEX $20 \mathrm{mg}$ (i.v.) & - & 2 & 4 \\
\hline OND 8 mg (i.v.) + DEX 20 mg (i.v.) & - & 1 & - \\
\hline TRO 5 mg (i.v.) + DEX 20 mg (i.v.) & $\begin{array}{l}\text { TROP } 5 \mathrm{mg} \text { (p.o.) + DEX } 16 \mathrm{mg} \text { (р.o.) (2 days) } \\
\text { TROP } 5 \mathrm{mg} \text { (p.o.) + DEX } 8 \mathrm{mg} \text { (р.o.) (2 days) }\end{array}$ & 2 & 2 \\
\hline TRO $5 \mathrm{mg}$ (i.v.) + OND $12 \mathrm{mg}$ (p.o.) + DEX $20 \mathrm{mg}$ (i.v.) & OND 12 mg (p.o.) (4 days) & 1 & - \\
\hline TRO 5 mg (i.v.) + DEX 20 mg (i.v.) & $\begin{array}{l}\text { OND } 4 \mathrm{mg} \text { (р.o.) + DEX } 16 \mathrm{mg} \text { (р.о.) (2 days) } \\
\text { OND } 4 \mathrm{mg} \text { (p.o.) + DEX } 8 \mathrm{mg} \text { (р.о.) (2 days) }\end{array}$ & - & 1 \\
\hline TRO 5 mg (i.v.) + GRA 1 mg (p.o.) + DEX 20 mg (i.v.) & GRA $1 \mathrm{mg}$ (p.o.) (4 days) & - & 1 \\
\hline TRO $5 \mathrm{mg}$ (i.v.) + metoclopramide $30 \mathrm{mg}$ (p.o.) + DEX $20 \mathrm{mg}$ (i.v.) & Metoclopramide (p.o.) (4 days) & - & 1 \\
\hline OND $8 \mathrm{mg}$ (i.v.) + TRO $5 \mathrm{mg}$ (i.v.) + DEX $20 \mathrm{mg}$ (i.v.) & $\begin{array}{l}\text { OND } 30 \mathrm{mg} \text { (р.o.) + DEX } 16 \mathrm{mg} \text { (p.o.) (2 days) } \\
\text { OND } 20 \mathrm{mg} \text { (p.o.) + DEX } 8 \mathrm{mg} \text { (p.o.) (2 days) }\end{array}$ & 1 & - \\
\hline
\end{tabular}

OND, ondansetron; DEX, dexamethasone; TRO, tropisetron; GRA, granisetron; p.o., oral route; i.v., intravenous.

\section{Table 3}

Proportion of patients reaching secondary or exploratory end points

\begin{tabular}{|c|c|c|c|}
\hline & CBM $n=7$ & Placebo $n=9$ & Difference (\%) $(95 \% \mathrm{Cl})$ \\
\hline No delayed emesis & $5(71.4 \%)$ & $2(22.2 \%)$ & $49.2(1.0,75.0)$ \\
\hline No delayed nausea* & $4(57.1 \%)$ & $2(22.2 \%)$ & $34.9(-10.8,66.3)$ \\
\hline No significant delayed nauseat & $5(71.4 \%)$ & $4(44.4 \%)$ & $27.0(-18.0,59.7)$ \\
\hline Not valued & $1 \neq(14.3 \%)$ & - & \\
\hline
\end{tabular}

*Nausea VAS score of $\leq 10 \mathrm{~mm}$. TNausea VAS score of $\leq 25 \mathrm{~mm}$. $\neq$ One patient in the CBM group discontinued treatment after the first three doses in the hospital and did not complete the assessment questionnaire.

ondansetron was not more effective than either drug alone [19]. The main differences between our study and this clinical trial were the medicines tested (dronabinol vs. $\mathrm{THC}+\mathrm{CBD}$ ), the population included (patients resistant to anti-emetic prophylaxis in our study), and the CINV prophylaxis used (dexamethasone limited to the first day of treatment and ondansetron with or without dronabinol thereafter in all patients in Meiri's study while in our study half the patients did not receive any treatment for delayed CINV while most of the other patients received a corticosteroid in addition to a $5-\mathrm{HT}_{3} \mathrm{R}$ antagonist). The pilot nature of our study precludes reaching firm conclusions but results suggest a potential contribution of CBM in reducing CINV.

This is the first study using a short titration CBM period in CINV. Other studies using this CBM were carried out on chronic diseases with a slower dose escalation period between 10 and 15 days. In spite of the faster titration dose used in this study, the frequency of ADRs was similar to the studies using slower titration regimens.

Plasma concentrations of the active principles and metabolites showed a wide intersubject variability, a result expected with CBM [20] and which may also reflect wide variability in the doses actually taken by patients, as planned for in the study protocol. Mean plasma concentra- tions of THC and CBD were similar, in agreement with the formulation of the CBM which has a ratio THC : CBD of 1:1. Our data suggest that patients following the repeated administration schedule accumulate CBM active compounds in plasma over time, despite the relatively short half-life of THC, CBD and 11-OH-THC (of 84, 109, and 130 min, respectively, GW Pharmaceuticals, UK). Although plasma concentrations of the active principles were undetectable at baseline and 60 min after CBM administration, they were already present $4 \mathrm{~h}$ afterwards. Previous reports have shown that peak plasma concentrations $\left(t_{\max }\right)$ are reached at 263, 253 and $230 \mathrm{~min}$ for THC, CBD and 11-OH$\mathrm{THC}$, respectively [20]. The relatively high concentrations of $\mathrm{THC}-\mathrm{COOH}$ found relative to its parent compound THC are equally a result of the accumulation of this terminal metabolite over time. Taking into account the pharmacokinetic results, the design of confirmatory clinical trials should take into consideration a possible delay in the administration of the second dose and a different PK sampling strategy to characterize fully the fast titration approach of CBM in these patients.

The main limitation of our study was the low number of patients included given the relatively heterogeneous population of the participating patients, in terms of type of cancer and of the chemotherapeutic agents involved. The 


\section{Table 4}

Summary of adverse events

\begin{tabular}{|c|c|c|}
\hline Adverse events & Sativex $^{\circledR}(n=7)$ & Placebo $(n=9)$ \\
\hline Somnolence & 4 & 4 \\
\hline Dry mouth & 2 & 3 \\
\hline Fatigue & 1 & 4 \\
\hline Dizziness & 3 & 1 \\
\hline Anxiety & 2 & - \\
\hline Confusion & 2 & - \\
\hline Insomnia & 1 & 1 \\
\hline Blurred vision & 1 & 1 \\
\hline Tachycardia & 1 & 1 \\
\hline Dysgeusia & - & 2 \\
\hline Vomiting after administration & - & 2 \\
\hline Alteration of memory & 1 & - \\
\hline Depression & 1 & - \\
\hline Psychosis & 1 & - \\
\hline Euphoric mood & - & 1 \\
\hline Oral pain & - & 1 \\
\hline Throat irritation & 1 & - \\
\hline Aerophagy & 1 & - \\
\hline Mouth ulceration & - & 1 \\
\hline Anorexia & - & 1 \\
\hline Epigastralgia & - & 1 \\
\hline Feeling abnormal & - & 1 \\
\hline Total adverse events & 22 & 25 \\
\hline Total patients & $6(86 \%)$ & $6(67 \%)$ \\
\hline
\end{tabular}

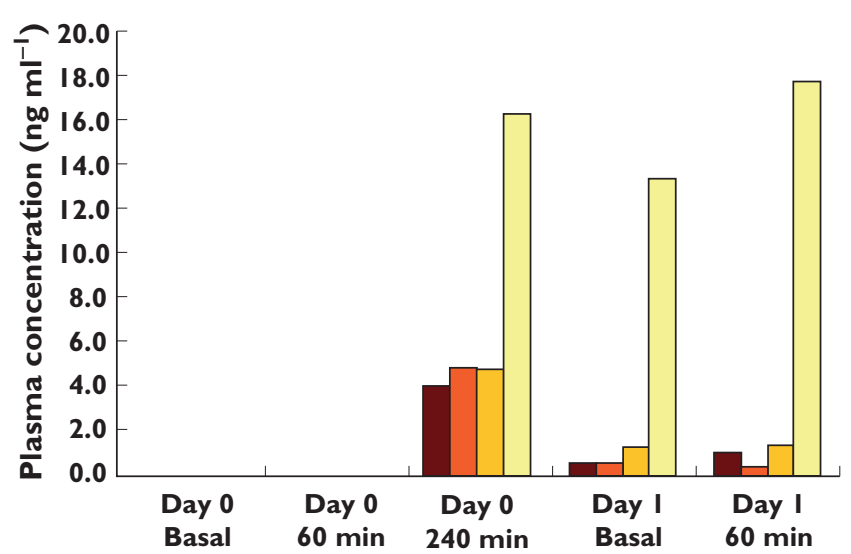

\section{Figure 2}

Plasma concentration of CBM active components and metabolites at each point of extraction. CBD $(\square)$; THC ( $\square)$; 11-OH-THC ( $\square)$; THC-COOH (

main reason for non participation among patients who refused to be enrolled was that treatment for only one chemotherapy cycle was offered. Limited funding also contributed to the low number of participants. The physicians in charge were not offered any monetary compensation for recruiting patients into the trial. The large amount of research in the oncology services favours competitiveness in the recruitment and the absence of funding in our study could have contributed to the low number of participants.
Variance among groups in types of cancer may have affected the results. Although the basal antiemetic treatment was similar in both groups this could also have had an impact on the results due to the small sample size. Standard treatment was not defined a priori and the regimens were the ones used in each hospital's protocol to respect the exploratory condition of the study and to be close to clinical practice.

Optimizing the treatment for CINV will most probably focus on identifying combinations of several drugs interacting with the various neurotransmitter systems involved in nausea and vomiting reflexes. In this endeavour, the potential of CBMs should not be overlooked. Our study is the first on a cannabis-based medicine containing THC and CBD in the prevention of CINV. It contributes to our knowledge on CBM administration and on its efficacy and tolerability, which will be of value in the design of further larger phase III clinical trials.

\section{Competing interests}

There are no competing interests to declare.

We are most grateful to all patients who accepted to participate in this study. Margarita Majem has been partially supported by Red Temática de Investigación Cooperativa en Cáncer (RTICC), and a grant from Departament d'Innovació, Universitats i Empreses (DIUE), Generalitat de Catalunya. The financial support for this study was provided by the Agència d'Avaluació de Tecnologia i Recerca Mèdiques (AATRM), Departament de Salut de la Generalitat de Catalunya.

\section{REFERENCES}

1 Bloechl-Daum B, Deuson RR, Mavros P, Hansen M, Herrstedt J. Delayed nausea and vomiting continue to reduce patients' quality of life after highly and moderately emetogenic chemotherapy despite antiemetic treatment. J Clin Oncol 2006; 24: 4472-8.

2 Kris MG, Hesketh PJ, Somerfield MR, Feyer P, Clark-Snow R, Koeller JM, Morrow GR, Chinnery LW, Chesney MJ, Gralla RJ, Grunberg SM. American Society of Clinical Oncology Guideline for Antiemetics in Oncology: update 2006. J Clin Oncol 2006; 24: 2932-47.

3 Slatkin NE. Cannabinoids in the treatment of chemotherapy-induced nausea and vomiting: beyond prevention of acute emesis. J Support Oncol 2007; 5 (Suppl. 3) $\mathrm{S} 1-9$.

4 Duran M, de las Heras MJ, Laporte JR, Capellà D. Uso terapéutico del cannabis: resultados de una entrevista prospectiva en Cataluña. Med Clin (Barc) 2005; 124: 76-7.

5 Pertwee RG. The diverse CB1 and CB2 receptor pharmacology of three plant cannabinoids: 
delta9-tetrahydrocannabinol, cannabidiol and delta9-tetrahydrocannabivarin. Br J Pharmacol 2008; 153: 199-215.

6 Sanger GJ. Endocannabinoids and the gastrointestinal tract: what are the key questions? Br J Pharmacol 2007; 152: 663-70.

7 Van Sickle DD, Duncan M, Kingsley PJ, Mouihate A, Urbani P, Mackie K, Stella N, Makriyannis A, Piomelli D, Davison JS, Marnett LJ, Di Marzo V, Pittman QJ, Patel KD, Sharkey KA. Identification and functional characterization of brainstem cannabinoid CB2 receptors. Science 2005; 310: 329-32.

8 Tramèr MR, Carroll D, Campbell FA, Reynolds DJ, Moore RA, McQuay HJ. Cannabinoids for control of chemotherapy induced nausea and vomiting, quantitative systematic review. BMJ 2001; 323: 16-21.

9 Grotenhermen F. Pharmacokinetics and pharmacodynamics of cannabinoids. Clin Pharmacokinet 2003; 42: 327-60.

10 Parker LA, Mechoulam R, Schlievert C. Cannabidiol, a non-psychoactive component of cannabis and its synthetic dimethylheptyl homolog suppress nausea in an experimental model with rats. Neuroreport 2002; 13: 567-70.

11 Di Marzo V, Petrocelli LD. Plant, synthetic, and endogenous cannabinoids in medicine. Annu Rev Med 2006; 57: 553-74.

12 Wade DT, Robson P, House H, Makela P, Aram J. A preliminary controlled study to determine whether whole-plant cannabis extracts can improve intractable neurogenic symptoms. Clin Rehabil 2003; 17: 21-9.

13 Colin C, Davies P, Mutiboko IK, Ratcliffe S, Sativex Spasticity in MS Study Group. Randomized controlled trial of cannabis-based medicine in spasticity caused by multiple sclerosis. Eur J Neurol 2007; 14: 290-6.
14 Wade DT, Makela PM, House H, Bateman C, Robson P. Long-term use of a cannabis-based medicine in the treatment of spasticity and other symptoms in multiple sclerosis. Mult Scler 2006; 12: 639-45.

15 Carnrike CLM, Brantley PJ, Bruce B, Faruqui S, Gresham FM, Buss RR, Cocke TB. Test-retest reliability and concurrent validity of the Morrow assessment of nausea and emesis (MANE) for the assessment of cancer chemotherapy-related nausea and vomiting. J Psychopathol Behav Assess 1988; 10: 105-16.

16 Martin AR, Pearson JD, Cai B, Elmer M, Horgan K, Lindley C. Assessing the impact of chemotherapy-induced nausea and vomiting on patients' daily lives: a modified version of the Functional Living Index-Emesis (FLIE) with 5-day recall. Support Care Cancer 2003; 11: 522-7.

17 Kemp PM, Abukhalaf IK, Manno JE, Manno BR, Alford DD, Abusada GA. Cannabinoids in humans. I. Analysis of delta 9-tetrahydrocannabinol and six metabolites in plasma and urine using GC-MS. J Anal Toxicol 1995; 19: 285-91.

18 Newcombe RG, Altman DG. Proportions and their differences. In: Statistics with Confidence, eds Altman DG, Machin D, Bryant TN, Gardner MJ. London: BMJ Publishing Books, 2000; 49-50.

19 Meiri E, Jhangiani H, Vredenburgh JJ, Barbato LM, Carter FJ, Yang HM, Baranowski V. Efficacy of dronabinol alone and in combination with ondansetron versus ondansetron alone for delayed chemotherapy-induced nausea and vomiting. Curr Med Res Opin 2007; 23: 533-43.

20 Smith PF. GW-1000. GW Pharmaceuticals. Curr Opin Investig Drugs $2004 ; 5: 748-54$. 